\title{
Progesterone alters the bovine uterine fluid lipidome during the period of elongation
}

\author{
Constantine A Simintiras, José M Sánchez, Michael McDonald and Pat Lonergan \\ School of Agriculture and Food Science, University College Dublin, Belfield, Dublin 4, Ireland \\ Correspondence should be addressed to P Lonergan; Email: pat.lonergan@ucd.ie
}

\begin{abstract}
Successful bovine pregnancy establishment hinges on conceptus elongation, a key reproductive phenomenon coinciding with the period during which most pregnancies fail. Elongation is yet to be recapitulated in vitro, whereas in vivo it is directly driven by uterine secretions and indirectly influenced by prior circulating progesterone levels. To better understand the microenvironment evolved to facilitate this fundamental developmental event, uterine fluid was recovered on Days 12-14 of the oestrous cycle - the window of conceptus elongation initiation - from cycling heifers supplemented, or not, with progesterone. Subsequent lipidomic profiling of uterine luminal fluid by advanced high-throughput metabolomics revealed the consistent presence of 75 metabolites, of which $47 \%$ were intricately linked to membrane biogenesis, and with seven displaying a day by progesterone interaction $(P \leq 0.05)$. Four metabolic pathways were correspondingly enriched according to day and P4 - i.e. comprised metabolites whose concentrations differed between groups (normal vs high P4) at different times (Days 12 vs 13 vs 14). These were inositol, phospholipid, glycerolipid and primary bile acid metabolism. Moreover, P4 elevated total uterine luminal fluid lipid content on Day $14(P<0.0001)$ relative to all other comparisons. The data combined suggest that maternal lipid supply during the elongation-initiation window is primarily geared towards conceptus membrane biogenesis. In summary, progesterone supplementation alters the lipidomic profile of bovine uterine fluid during the period of conceptus elongation initiation.

Reproduction (2019) 157 399-411
\end{abstract}

\section{Introduction}

Conceptus elongation in ruminants is a prerequisite for apposition, attachment and implantation, rendering it essential for pregnancy establishment (Bazer et al. 2017). The process of elongation is characterized by extraembryonic membrane differentiation (Hue et al. 2012), morphological transition from spherical to ovoid to tubular to filamentous structure (Brooks et al. 2014), and a rapid increase in trophectoderm weight and length (Wales \& Cuneo 1989, Rizos et al. 2012, Spencer et al. 2016). Bovine conceptus elongation typically initiates on Day 13 post oestrus (Betteridge et al. 1980, Berg et al. 2011, Brooks et al. 2014) and continues until approximately Day 20 (Guillomot 1995), by which time it can exceed $20 \mathrm{~cm}$ in length (Hue et al. 2012, Brooks et al. 2014). The process of elongation is, therefore, likely to be considerably energetically and metabolically demanding. This is corroborated by (a) the majority of genes expressed in the early elongation bovine conceptus relating to metabolism (Degrelle et al. 2005, Mamo et al. 2011), (b) a greater enrichment of differentially expressed gene pathways relating to metabolism and biosynthesis in long vs short conceptuses (Barnwell et al. 2016, Ribeiro et al. 2016a) and (c) the dependency of the elongating conceptus on endometrial secretions - unlike the relatively autonomous early embryo, the posthatching conceptus will neither elongate in vivo in the absence of uterine glands (Gray et al. 2001) nor in vitro (Brandão et al. 2004).

It is also understood that the rate of conceptus elongation is positively correlated to early maternally circulating progesterone (P4) concentrations. In vitroderived blastocysts transferred into uteri primed by elevated P4 exhibit advanced conceptus elongation on Day 14 (Clemente et al. 2009). Conversely, conceptus elongation is perturbed in animals with pathophysiologically low P4 (Forde et al. 2012). The process of elongation is, therefore, (a) P4 correlated, (b) maternally driven (dependent on the endometrial secretions) and (c) essential to pregnancy establishment (Lonergan 2015). Regarding the latter, the conceptus elongation window coincides with a period of significant embryo loss in cattle (Diskin \& Sreenan 1980, Walsh et al. 2011, Wiltbank et al. 2016). It is estimated that one-third of viable blastocysts fail to elongate (Diskin \& Sreenan 1980, Ribeiro et al. 2016b) and therefore cannot secrete sufficient amounts of the pregnancy recognition signal, interferon $\operatorname{tau}(\mathrm{IFN} \tau)$ - the production of which is proportional to conceptus size (Kerbler et al. 1997, Rizos et al. 2012). In turn, uterine oxytocin receptor upregulation inhibition for subsequent 
luteolysis prevention is perturbed and pregnancy establishment cannot occur (Binelli et al. 2001, Forde \& Lonergan 2017).

The importance of lipids to conceptus elongation has been investigated to a relatively limited extent. Ovine uterine caruncular epithelial lipid abundance was reduced in the presence of an elongating conceptus (Boshier et al. 1987), and the physiological elevation of P4 during diestrus induced an accumulation of lipids in the ovine endometrium (Brinsfield \& Hawk 1973). Furthermore, pregnancy had a major impact on the lipidomic profile of uterine luminal fluid (ULF) flushes from Day 15 pregnant and cyclic lactating dairy cows (Ribeiro et al. 2016a), and the greatest difference in gene expression between tubular vs filamentous conceptuses recovered was in those associated with lipid metabolism - specifically polyunsaturated fatty acid conversion, phospholipid metabolism and prostaglandin modification (12). For a detailed review on the role of lipids on ruminant conceptus elongation, see Ribeiro et al. (2016c).

We recently showed that the amino acid and carbohydrate composition of bovine ULF on Days 12-14 post oestrus was affected by P4 supplementation, revealing several metabolites of likely importance to the process of conceptus elongation initiation (Simintiras et al. 2018). Given the biological significance of lipids - major constituents of plasma and nuclear membranes, the endoplasmic reticulum and the Golgi apparatus (Muro et al. 2014) in addition to extracellular vesicles (Brooks et al. 2014, Burns et al. 2014) - our hypothesis was that a high-throughput lipidomic profiling of these ULF samples would identify several additional molecules which are likely central to driving and sustaining conceptus elongation. The specific aim, therefore, was to analyse the lipid fraction of ULF obtained on Days 12-14 from cycling heifers with normal vs high P4 in circulation, a model known to advance the rate of elongation (Carter et al. 2008, O'Hara et al. 2014a,b).

\section{Materials and methods}

Sample collection is described in detail in (Simintiras et al. 2018); however, a summary is provided below.

\section{Animals}

All animal work was approved by the University College Dublin (UCD) Animal Research Ethics Committee (AREC) and licensed by the Irish Health Products Regulatory Authority (HPRA) and was performed in accordance with the European Community Directive 2010/63/EU. The oestrous cycles of 35 Charolais and Limousin crossbred heifers with a mean age ( \pm S.D.) of $24.9 \pm 5.6$ months and weight $( \pm$ S.D.) of $601.6 \pm 47.7 \mathrm{~kg}$ were synchronized with an injection of gonadotropin-releasing hormone $(\mathrm{GnRH})$ analogue (Ovarelin, Ceva Santé Animale) immediately prior to the insertion of a P4-releasing intravaginal
}

device (PRID; Ceva Santé Animale). After 7 days, all animals were injected with a prostaglandin F2 $\alpha$ (PGF2 $\alpha$ ) analogue (Enzaprost; Ceva Santé Animale) with PRID removal the following day. On Day 3 post oestrus, 20 randomly allocated heifers received another PRID until slaughter (high P4 group). The remaining 15 animals comprised the normal P4 group.

\section{Experimental design}

Experimental group allocations were as follows: (i) Day 12 normal P4 $(n=6)$, (ii) Day 12 high P4 $(n=6)$, (iii) Day 13 normal P4 $(n=4)$, (vi) Day 13 high P4 $(n=8)$, (v) Day 14 normal P4 $(n=5)$ and (vi) Day 14 high P4 $(n=6)$.

\section{Progesterone analysis}

Blood was taken from all heifers by coccygeal venepuncture on Days 3 and 5 in addition to the day of slaughter (Days 12-14), prior to cooling for $24 \mathrm{~h}$ at $4^{\circ} \mathrm{C}$. Blood samples were then centrifuged for $20 \mathrm{~min}$ at $1500 \mathrm{~g}$ at $4^{\circ} \mathrm{C}$ to recover the serumcontaining supernatant, which was kept at $-20^{\circ} \mathrm{C}$ until P4 concentration measurement by solid-phase radioimmunoassay (PROG-RIA-CT kit, DIAsource).

\section{Uterine luminal fluid recovery}

The uterine horn ipsilateral to the $\mathrm{CL}$ was excised within $30 \mathrm{~min}$ of slaughter, flushed with $10 \mathrm{~mL}$ phosphate buffered saline (PBS; Sigma Aldrich), and centrifuged for $15 \mathrm{~min}$ at $1000 \mathrm{~g}$. The supernatant was aliquoted, snap-frozen in liquid nitrogen and stored at $-80^{\circ} \mathrm{C}$ until analysis.

\section{Metabolomic analyses}

As previously elaborated upon (Simintiras et al. 2018), sample preparation and analysis by ultrahigh performance liquid chromatography-tandem mass spectroscopy (UPLC-MS/MS) was performed by Metabolon Inc. In brief, samples were analysed by four separate reverse-phase (RP/UPLC)-MS/MS methods involving positive and negative ion mode electrospray ionization, in addition to hydrophilic interaction chromatography UPLC-MS/MS. Biochemicals were quantified against known internal and recovery standards, run in parallel at random intervals, and identified by retention time and a $\mathrm{m} / \mathrm{z}$ within $\pm 10 \mathrm{ppm}$. The technical median relative standard deviation was $5 \%$.

\section{Data extraction and analysis}

Data were corrected for variations resulting from instrument inter-day tuning differences; median peak areas for each metabolite were registered as 1.00 prior to normalizing each data point proportionally. Similar to Do et al. (2018), biochemical data were subsequently logarithmically transformed, missing values, if any, were imputed with the minimum observed value for each compound and quantified by relative abundance using MetaboLync pathway analysis (MPA) software (portal.metabolon.com), wherein statistical 
|

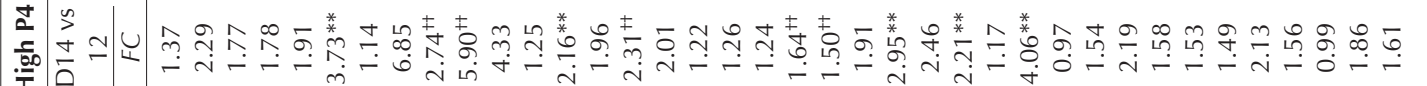

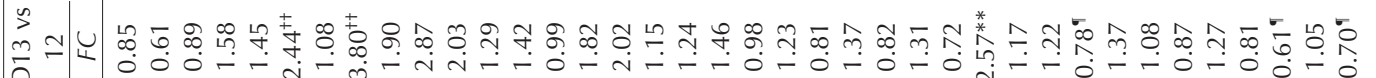

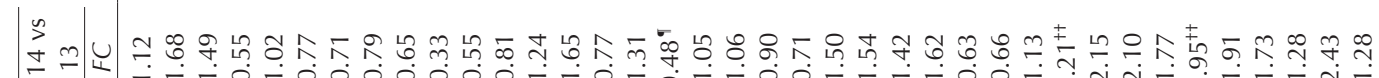

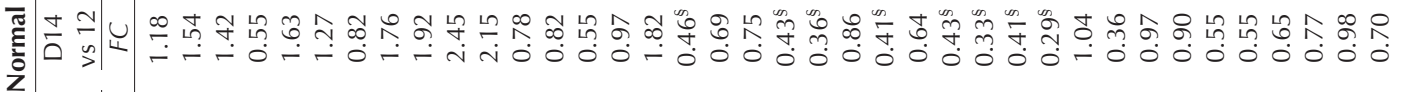

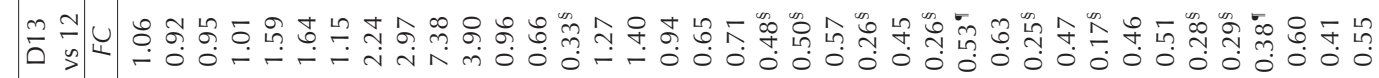

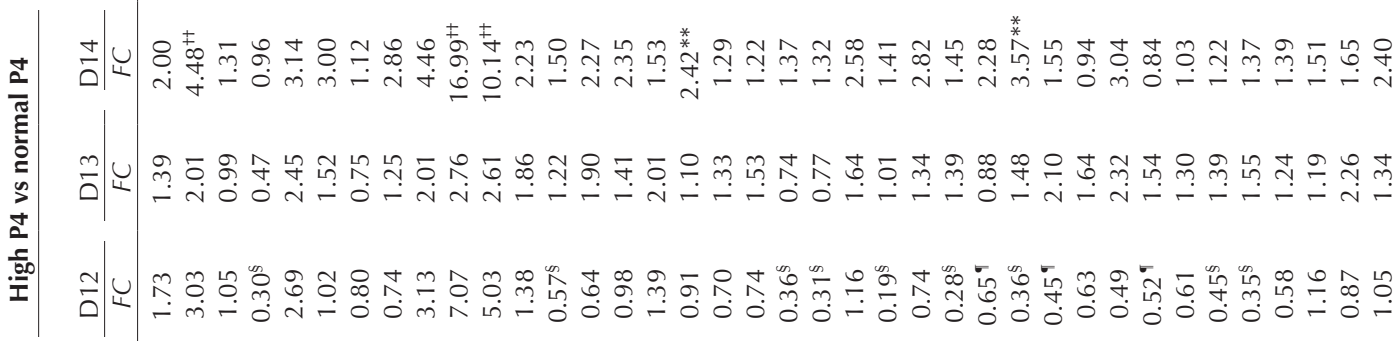
ตสกำ ㅇำ 0 至

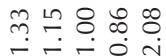
N $000 \%$

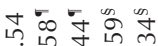
०००ण0

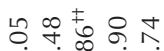
$i-\underset{j}{\infty}-\dot{0}$ ํํ욤 $\dot{0} \dot{-}+\dot{0}$

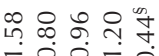

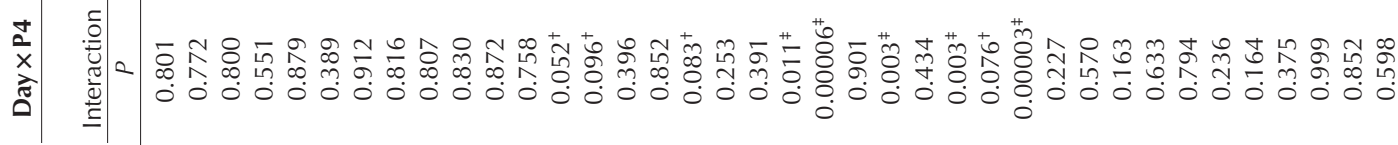

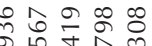
0000

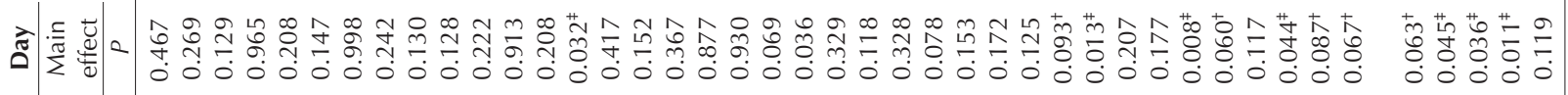

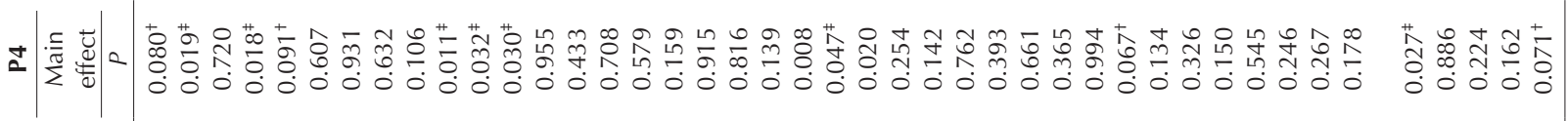

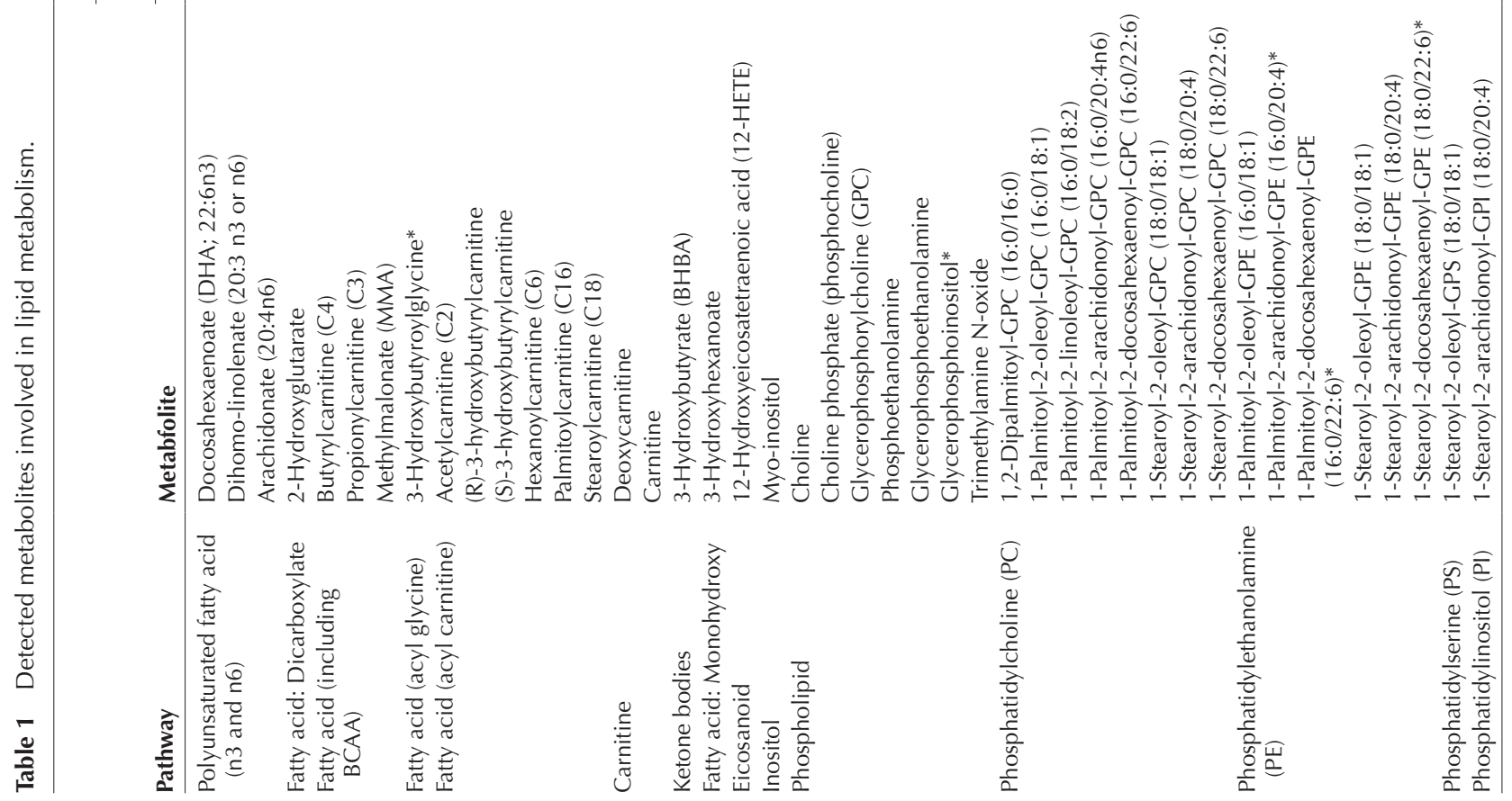




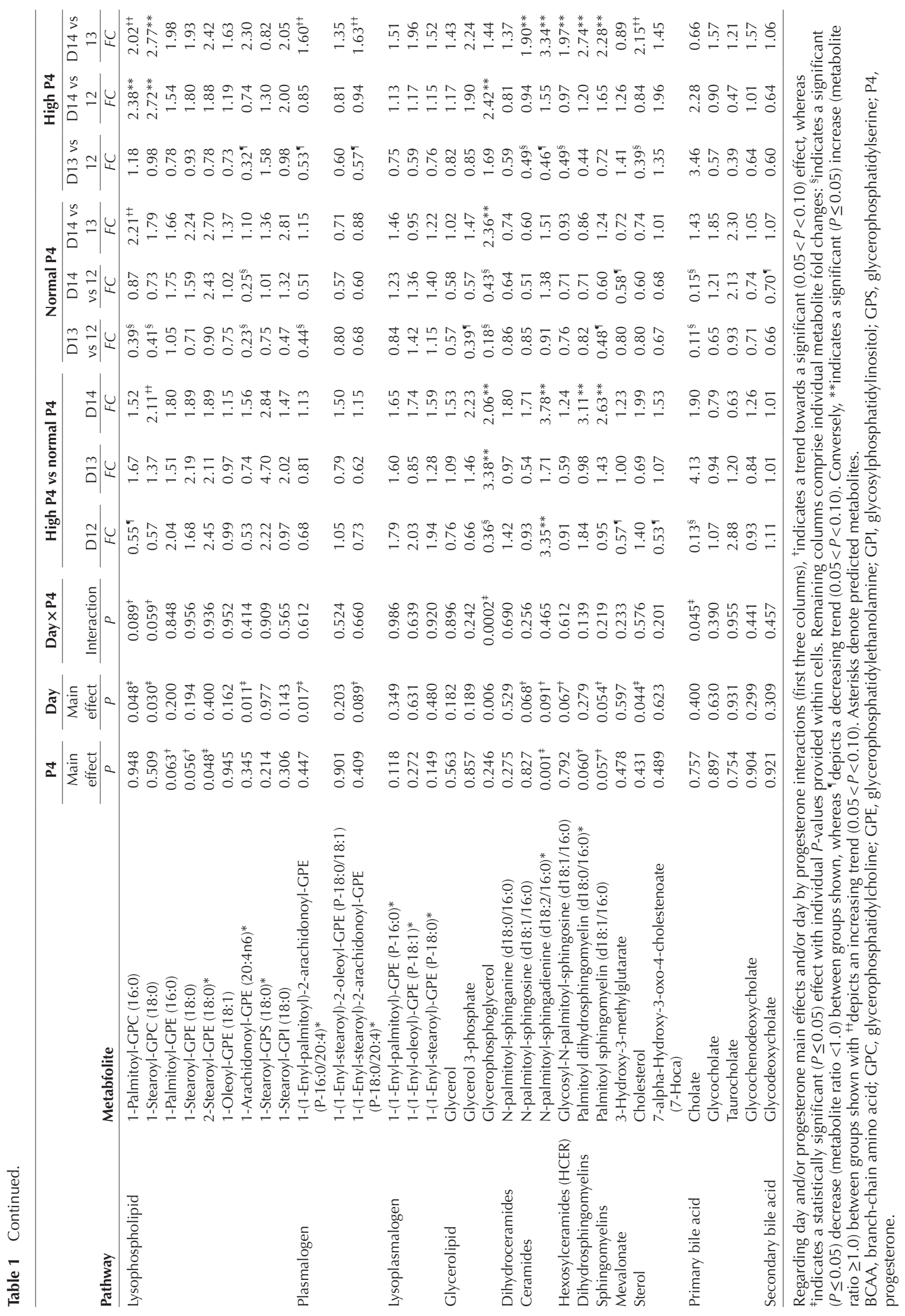


comparisons were made by two-way ANOVA with a $P \leq 0.05$ or $0.05<P<0.10$ cut off. pathway enrichment $-\mathrm{a}$ measure of intra-pathway metabolite flux relative to interpathway metabolite flux - was calculated within MPA using the following formula: $(k / m) /(n / N)$ where $k=$ the number of significant metabolites per pathway, $m=$ total number of detected metabolites per pathway, $n=$ the number of significant metabolites in the study and $N=$ the total number of detected metabolites in the study, similarly to Brown et al. (2016). Data were visualized using Java Cytoscape 3.6.1 and relative mean lipid concentrations were calculated by averaging the median scaled imputed data of all metabolites for each aforementioned experimental group. Moreover, unless otherwise stated, day and/or P4 biochemical and pathway enrichment main effects were discounted where biochemicals or pathways displayed a day by $\mathrm{P} 4$ interaction.

\section{Results}

Day 3 PRID insertion elevated serum P4 on Day 5 $(P \leq 0.05)$ from $1.53 \pm 0.163 \mathrm{ng} / \mathrm{mL}$ to $3.17 \pm 0.341 \mathrm{ng} / \mathrm{mL}$ ( \pm S.E.M.) (Simintiras et al. 2018).

Seventy-five lipid metabolites were consistently identified (Table 1), of which 28 were hormonally dynamic and/or temporally dynamic (Fig. 1). More specifically, nine exhibited a P4 main effect, that is differed $(P \leq 0.05)$ between high vs normal P4 heifers irrespective of day (1-stearoyl2-oleoyl-glycerophosphatidylethanolamine (GPE), 2-hydroxyglutarate, 2-stearoyl-GPE, choline phosphate, dihomo-linoleate, hexanoylcarnitine, N-palmitoylsphigadienine, (R)-3-hydroxybutyrylcarnitine, and (S)-3hydroxybutyrylcarnitine (Figs 1 and 2A)), 12 displayed a day main effect, that is an effect of time was observed $(P \leq 0.05)$ which was independent of P4 (1-(1-enylpalmitoyl)-2-arachidonoyl-G PE, 1-arachidonoyl-GPE, 1-palmitoyl-2-linoleoyl- glycerophosphatidylcholine (GPC), 1-palmitoyl-2-oleoyl-GPE, 1-palmitoylGPC, 1-stearoyl-2-arachidonoyl-GPE, 1-stearoyl-2docosahexaenoyl-GPE, 1-stearoyl-2-oleoyl-GPC, 1-stearoyl-2-oleoyl-glycerophosphatidylserine (GPS), cholesterol, and stearoylcarnitine (Figs 1 and 2B)) and seven metabolites showed a day by P4 interaction, that is the effect of day was dependent on P4 and vice versa (cholate, choline, glycerophosphoethanolamine, glycerophosphoglycerol, GPC, myo-inositol, and trimethylamine $\mathrm{N}$-oxide (Figs 1 and $2 \mathrm{C}$ )).

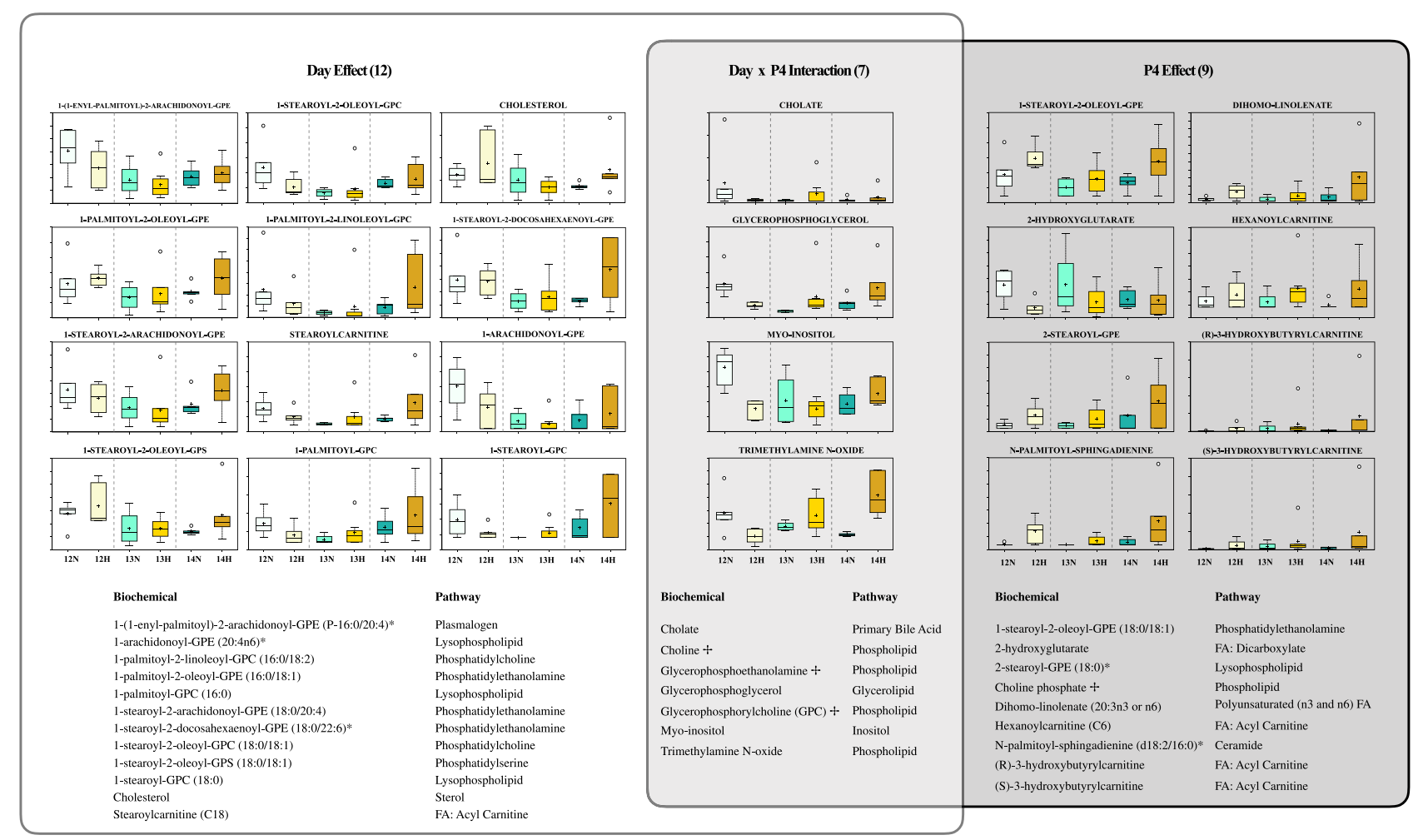

Figure 1 Venn diagram comprising the identified metabolites and their respective pathways showing a day main effect (left), a progesterone main effect (right) and/or a day by progesterone interaction (overlap). Corresponding metabolite scaled intensities are also provided, wherein the central horizontal line represents the median value with outer boundaries depicting upper and lower quartile limits. Error bars depict the minimum and maximum distributions, with a simple cross (+) representing the mean value and a white circle $(O)$ the extreme data point. Within tables, asterisks $\left({ }^{*}\right)$ denote predicted metabolites, whereas a tapered cross $(\mathbb{\nabla})$ depicts metabolites whose scaled intensity plots are provided elsewhere. 12H, Day 12 High P4; 12N, Day 12 Normal P4;13H, Day 13 High P4; 13N, Day 13 Normal P4; 14H, Day 14 High P4; 14N, Day 14 Normal P4; FA, fatty acid; GPC, glycerophosphatidylcholine; GPE, glycerophosphatidylethanolamine; GPS, glycerophosphatidylserine; P4, progesterone. 


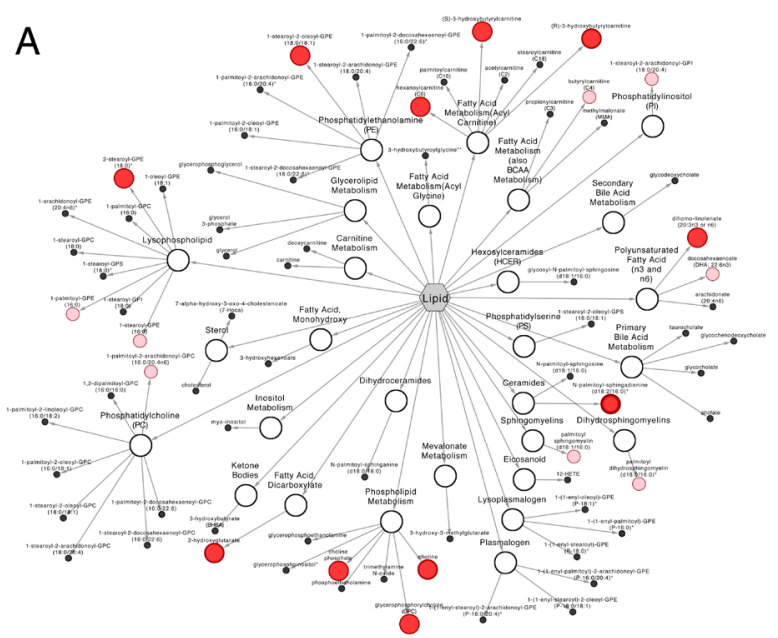

B
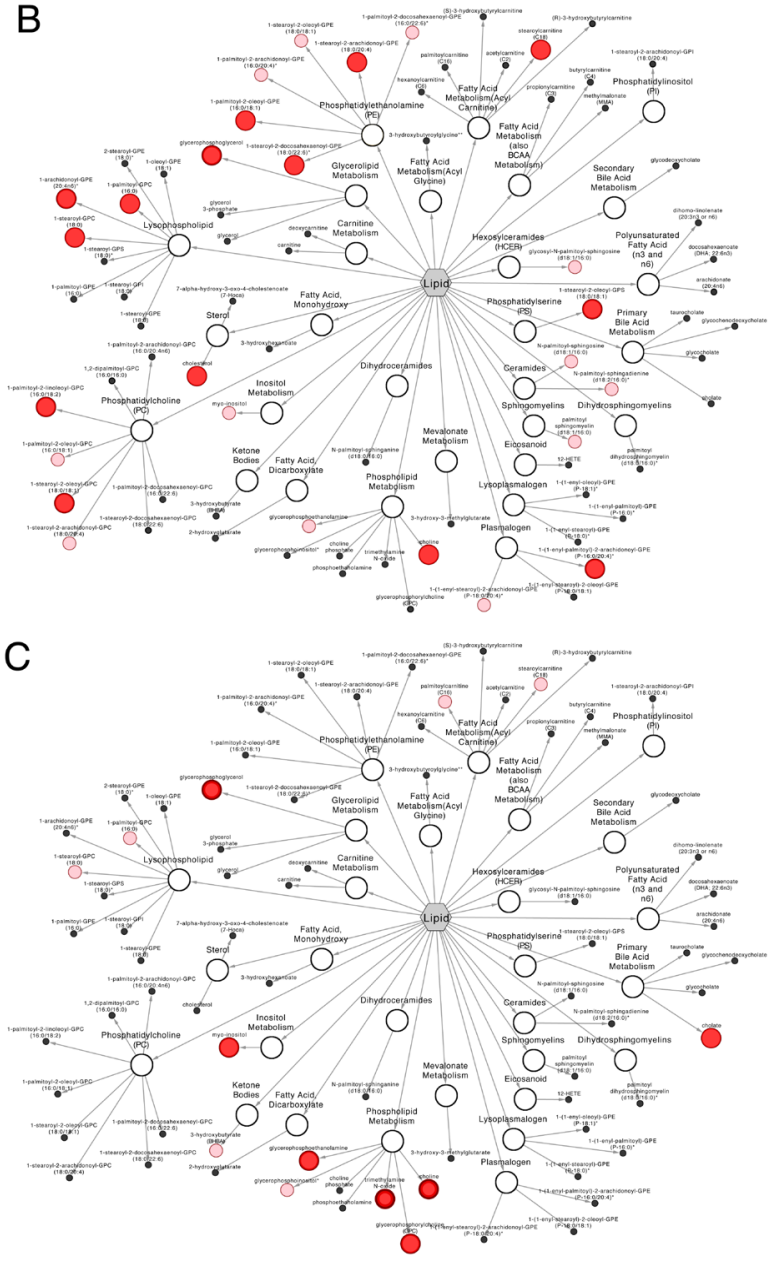

Figure 2 Network perspective of the biochemicals which displayed (A) a progesterone (P4) main effect, (B) a day main effect, and/or (C) a day by $\mathrm{P} 4$ interaction - i.e. concentrations differed between groups (normal vs high P4) at different times (Days 12 vs 13 vs 14).

Significance is represented by node colour and diameter combined: a large dark red node indicates an $(P \leq 0.05)$ effect/interaction (node border thickness is inversely proportional to the magnitude of the $P$-value), whereas a medium light red node depicts a trend $(0.05<P<0.10)$ towards an effect/interaction and small black nodes depict a lack of significance.
Seven metabolic pathways were temporally enriched, that is metabolites comprising these specific pathways exhibited greater flux in response to day relative to all other pathways. These, in addition to their pathway enrichment scores in brackets, were phosphatidylserine (6.7), phosphatidylethanolamine (3.3), sterol (3.3), lysophospholipid (2.2), plasmalogen (2.2), phosphatidylcholine (1.7) and acylcarnitine fatty acid (1.1) metabolism. Conversely, four pathways were hormonally enriched, that is comprised metabolites which significantly fluctuated more than those in other pathways between the normal and high P4 groups. These were dicarboxylate fatty acid (6.0), ceramide (3.0), acylcarnitine fatty acid (3.0) and polyunsaturated fatty acid (2.0) metabolism. One pathway, lysophospholipid (0.7), was temporally under-enriched, that is comprised less metabolites with statistically significant flux changes in response to elevated P4 relative to the analogous flux observed in all other pathways. Four pathways showed a day by P4 interaction, that is comprised metabolites whose concentrations differed between groups (normal vs high P4) at different times (Days 12 vs 13 vs 14). These were inositol (4.3), phospholipid (2.5), glycerolipid (1.4) and primary bile acid (1.1) metabolism (Fig. 3).

P4 had no effect on total uterine luminal lipid abundance on Day 12 (Fig. 4), despite reducing the concentrations of 12 lipids (Fig. 5A) by a mean ( \pm S.E.M.) fold-change of $0.34 \pm 0.03$, and increasing one, $\mathrm{N}$-palmitoyl-sphingadienine, by 3.35 -fold (Table 1 ). Similarly, P4 did not alter the total lipid profile on Day 13; high vs normal P4 lipid profiles were identical, in spite of a 3.38-fold elevation of glycerophosphoglycerol in the high P4 group (Fig. 5B; Table 1). By Day 14, however, P4 had a stimulatory effect - total lipid abundance was elevated $(P<0.0001)$ relative to the control. Moreover, total lipid content in the high P4 group was greater $(P<0.0001)$ on Day 14 compared to Days 12 and 13 (Fig. 5). Figure 5C depicts the increased $(P \leq 0.05)$ concentrations of six individual lipids by an average fold-change ( \pm S.E.M.) of $2.93 \pm 0.28$ in the Day 14 high vs normal P4 groups, in addition to the trending $(0.05<P<0.10)$ increase of five lipids within the same comparison.

Quantitative boxplots for detected metabolites directly involved in glycerophospholipid metabolism are provided in Fig. 6 . These are glycerophosphorylcholine (day by $\mathrm{P} 4$ interaction $(P=0.003)$ ), choline (day by $\mathrm{P} 4$ interaction $(P=0.00006)$ ), choline phosphate (day main effect $(P=0.047))$ and glycerophosphoethanolamine (day by $\mathrm{P} 4$ interaction $(P=0.003)$ ), in addition to phoshphoethanolamine and glycerol-3-phosphate, which were unaffected by day and P4. Boxplots for remaining metabolites, not provided in either Figs 1 or 6 , are provided in Supplementary Fig. 1 (see section on supplementary data given at the end of this article). These are 1-(1-enyl-oleoyl)-GPE, 


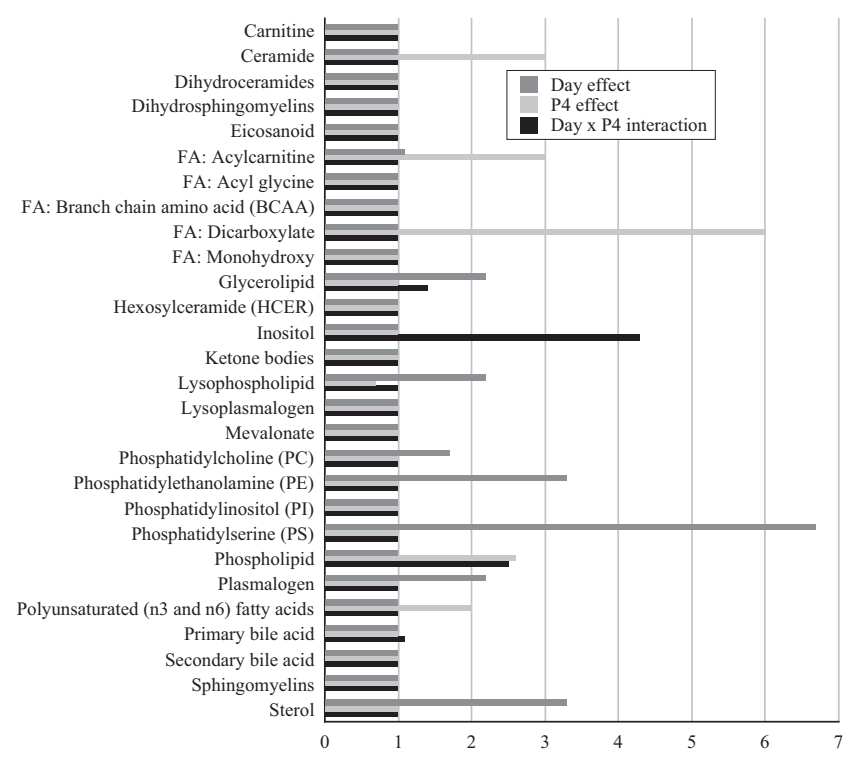

Figure 3 Pathway enrichment values by day or progesterone effect - i.e. pathways whose metabolites were generally temporally dynamic or hormonally responsive - and day by progesterone interaction - i.e. pathways in which the concentrations of metabolites differed between groups (normal vs high P4) at different times (Days 12 vs 13 vs 14). A score $>1$ indicates the pathway comprised a higher number of experimentally regulated compounds relative to the overall study for the specific comparison being made. A score of 1 depicts an unenriched pathway, whereas a score $<1$ indicates an under-represented pathway - i.e. the pathway comprised less metabolites with statistically significant fold differences compared to all other pathways in the study.

1-(1-enyl-palmitoyl)-GPE, 1-(1-enyl-stearoyl)-2arachidonoyl-GPE, 1-(1-enyl-stearoyl)-2-oleoyl-GPE, 1-(1-enyl-stearoyl)-GPE, 1-oleoyl-GPE, 1-palmitoyl-2arachidonoyl-GPC, 1-palmitoyl-2-arachidonoyl-GPE, 1-palmitoyl-2-docosahexaenoyl-GPC, 1-palmitoyl2-docosahexaenoyl-GPE, 1-palmitoyl-2-oleoyl-GPC, 1-palmitoyl-GPE, 1-stearoyl-2-arachidonoyl-GPC, 1-stearoyl-2-arachidonoyl-glycerophosphatidylinositol (GPI), 1-stearoyl-2-docosahexaenoyl-GPC, 1-stearoyl-GPE, 1-stearoyl-GPI, 1,2-dipalmitoylGPC, 12-hydroxyeicosatetraenoic acid, 3-hydroxy-3-methylglutarate, 3-hydroxybutyrate, 3-hydroxybutyroylglycine, 3-hydroxyhexanoate, 7-alpha-hydroxy-3-oxo-4-cholestenoate, acetylcarnitine, arachidonate, butyrylcarnitine, carnitine, deoxycarnitine, docosahexaenoate, glycerol, glycerophosphoinositol, glycochenodeoxycholate, glycocholate, glycodeoxycholate, glycosyl-npalmitoyl-sphingosine, methylmalonate, n-palmitoylsphinganine, n-palmitoyl-sphingosine, palmitoyl dihydrosphingomyelin, palmitoyl sphingomyelin, palmitoylcarnitine, propionylcarnitine and taurocholate - none of which were affected by day and P4 - in addition to 1-stearoyl-glycerophosphatidylserine, which exhibited a day main effect $(P=0.011)$.

\section{Discussion}

Lipids fulfil a plethora of fundamental biological roles ranging from energy and heat storage (anhydrous triacylglycerol reserves), compartmentalization (cellular and organelle phospholipid membranes), primary and secondary messaging (signal transduction via glycerolipid, sphingolipid and phosphatidylinositol catabolites), acting as substrates for post-translational protein-lipid modifications (e.g. palmitoylation, myristoylation, acylation and farnesylation) and protein recruitment platforms (e.g. lipid anchors) (van Meer et al. 2008, Saliba et al. 2015, Thukral et al. 2015, Resh 2016). In light of this, the lipid profile of uterine fluid from animals with high circulating P4 - a model known to accelerate conceptus elongation (Carter et al. 2008, O'Hara et al. 2014a,b) - has been analysed and compared with that from normal P4 animals, during the window of conceptus elongation-initiation (Days 12-14) using high-throughput untargeted metabolomics.

This study shows that elevated P4 augments total lipid content on Day 14 (Fig. 4) and that the specific pathways exhibiting a day by $\mathrm{P} 4$ interaction enrichment, and thus potentially important to conceptus elongation, are inositol, phospholipid, glycerolipid and primary bile acid metabolism (Fig. 2C). This suggests the uterine lipid supply during the elongation window is primarily geared towards membrane biogenesis, as opposed to signalling and energy provision, as discussed below.

There is little doubt that membrane biogenesis is essential for the approximately 30 -fold increase in conceptus trophoblast length between Days 12 and 15 (Betteridge et al. 1980, Brooks et al. 2014). In this study, $47 \%$ of identified lipids were intricately linked to membrane biochemistry; specifically, phospholipid, lysophospholipid, glycerolipid, phosphatidylcholine (PtdCho), phosphatidylethanolamine (PtdEtn), phosphatidylinositol (Ptdlns) and phosphatidylserine (PtdSer) metabolism (Table1). Moreover, the phospholipid and glycerolipid pathways (Fig. 6) represented half the metabolic pathways displaying day by $\mathrm{P} 4$ interaction enrichment (Fig. 2C), suggesting that ULF secretions directly aid conceptus membrane development (van Meer et al. 2008, van Meer \& de Kroon 2011). This is corroborated by the presence of PtdEtn-binding protein 1 (a murine sperm decapacitation factor; Gibbons et al. 2005, serine protease inhibitor; Hengst et al. 2001, and microtubule-associated protein (MAP) kinase pathway regulator, with an affinity for both PtdEtn and PtdCho; Vallée et al. 2001) in bovine ULF (Forde et al. 2014). Burns et al. (2018) recently observed that high circulating P4 increased the extracellular vesicle (EV) population in cyclic ovine uterine lumen on Days $12\left(\sim 4.5 \times 10^{10}\right)$ and $14\left(\sim 8.0 \times 10^{10}\right)$ relative to Day $10\left(\sim 1.5 \times 10^{10}\right)$, whilst EV median diameter remained unchanged. This increase in EV content by the high P4 ovine uterus, during the elongation window and prior to maternal pregnancy 


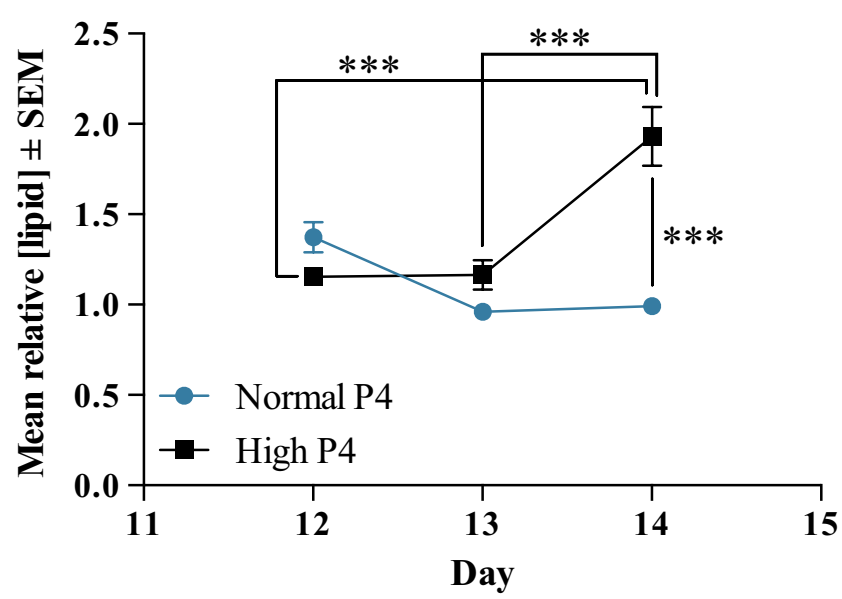

Figure 4 Relative concentrations ( \pm S.E.M.) of all lipid metabolites $(n=75)$ in the uterine luminal fluid of high progesterone animals relative to normal progesterone animals on Days 12, 13 and 14, wherein ${ }^{* * *}$ represents $P \leq 0.0001$.

recognition, is presumably available for conceptus fusion. These data combined corroborate the notion that lipid - whether free (Ribeiro et al. 2016a) and/or EV associated (Burns et al. 2018) - unavailability in conventional culture media may be a contributing factor to the current inability to achieve conceptus elongation in vitro.

Perhaps the best characterised lipids from a reproductive context are prostaglandins (Weems et al. 2006). Vilella et al. (2013) proposed measuring PGE $_{2}$ and $\mathrm{PGF}_{2 \alpha}$ as human endometrial receptivity biomarkers, and in ruminants, $\mathrm{PGF}_{2 \alpha}, \mathrm{PGE}_{2}, \mathrm{PGD}_{2}$ and 6-keto $\mathrm{PGF}_{1 \alpha}$ have been identified in pregnant and cyclic heifers on Days 12, 15 and 18 (Ulbrich et al. 2009). Prostaglandins (PGs) were not identified in this study; although this is likely attributable to the low concentrations of PG in ULF prior to Day 15 coupled with analytical insensitivity. For instance, approximately $7 \mathrm{pg} / \mathrm{mL} \mathrm{PGE}_{2}$ has been detected in bovine ULF on Day 12 (Ulbrich et al. 2009); however, the prostaglandin detection limit of conventional nontargeted mass-spectrometry-based systems, such as that employed in this study, is in the region of $20 \mathrm{pg} / \mathrm{mL}$ (Cao et al. 2008). Other studies, such as Dorniak et al. (2011), which specifically investigated ovine uterine PG content, utilized enzymatic PG detection methods.

Arachidonate, a key intermediate of PG synthesis (Ribeiro 2018) - and one of the most abundant lipids found by Ribeiro et al. (2016a) in Day 15 ULF flushes from pregnant and cyclic lactating dairy cows - was identified in this study (Supplementary Fig. 1) and was, moreover, elevated by P4 on Day 14 vs 13 (Table 1). If one extrapolates that a Day 14 high P4 luminal microenvironment is analogous to a normal P4 Day 16 uterine environment (Forde et al. 2009), the elevated luminal arachidonate observed corresponds to the increased demand for PG precursors by the conceptus. More specifically, Day 16 bovine pregnancy

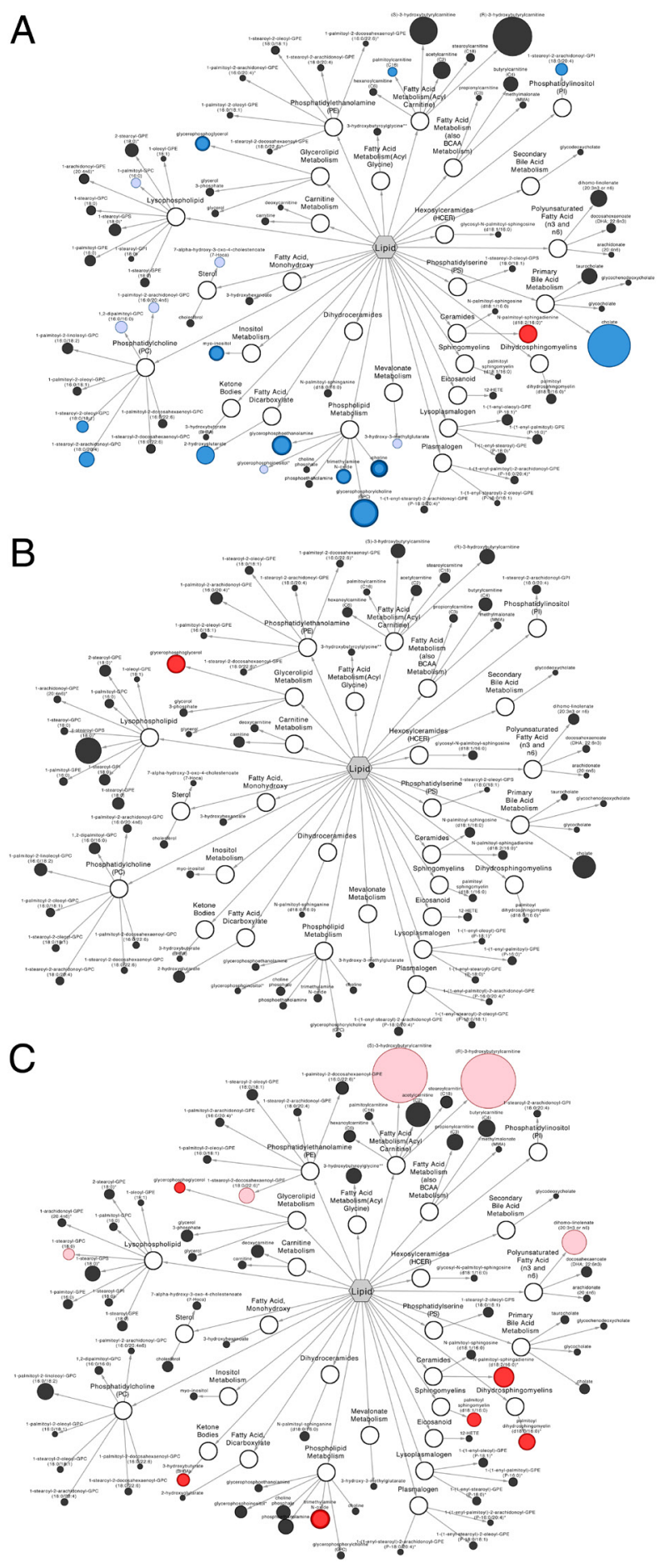

Figure 5 Network comparison of lipid metabolite relative flux in uterine luminal fluid by treatment (normal vs high progesterone) on (A) Day 12, (B) Day 13 and (C) Day 14. Node diameter is proportional to the fold change observed. Node colour represents the significance of the change: dark red depicting a significant $(P \leq 0.05)$ increase, light red highlighting an increasing trend $(0.05<P<0.10)$, dark blue denoting a significant $(P \leq 0.05)$ decrease, and light blue depicting a decreasing trend $(0.05<P<0.10)$. Black nodes depict a lack of a statistically significant flux. In addition to node colour, node border thickness is inversely proportional to the magnitude of the $P$ value.

https://rep.bioscientifica.com 


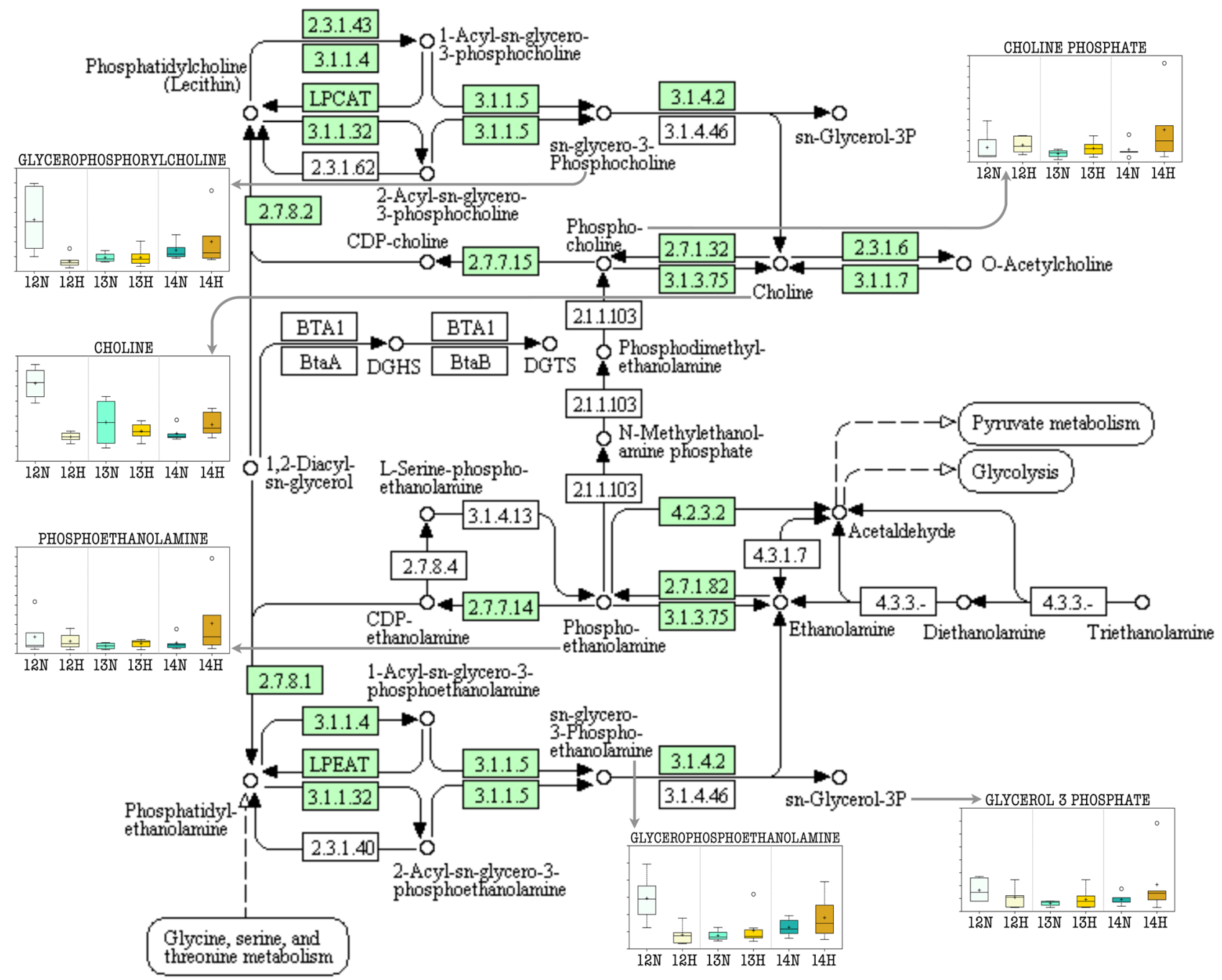

Figure 6 The glycerophospholipid metabolic pathway adapted from the Kyoto encyclopaedia of genes and genomes (KEGG) database. Numbers within boxes are the enzyme commission (EC) codes for enzymatic classification and highlighted enzymes have been identified in Bos taurus. Corresponding scaled intensities of relevant biochemicals are also provided wherein the central horizontal line represents the median value with outer boundaries depicting upper and lower quartile limits. Error bars depict the minimum and maximum distributions, with + representing the mean value and $\mathrm{O}$ the extreme data point. $12 \mathrm{H}$, Day 12 High P4; $12 \mathrm{~N}$, Day 12 Normal P4;13H, Day 13 High P4; 13N, Day 13 Normal P4; 14H, Day 14 High P4; 14N, Day 14 Normal P4.

is characterised, in part, by elevated conceptus-derived PG secretions (Lewis \& Waterman 1983, Brooks et al. 2014); the Day 16 ovine conceptus produces PG from arachidonate (Lewis \& Waterman 1983), prior to secretion for autocrine, paracrine and possibly intracrine signalling to the uterus and the conceptus itself (Bazer 2013).

A recent study investigating the impact of $\omega-3$ vs $\omega-6$-rich diets on conceptus elongation and ULF composition on Day 15 in heifers revealed, amongst other things, that (a) dietary $\omega-3$ supplementation led to greater conceptus elongation relative to an $\omega-6$ rich diet, (b) the $\omega-3$ group displayed elevated circulating P4 and (c) arachidonate was reduced in the ULF of heifers on the $\omega$-3-rich diet (Giller et al. 2018). These findings, together with reduced arachidonate in the ULF of pregnant vs cyclic lactating dairy cows on Day 15 (Ribeiro et al. 2016a), support the theory that uterine arachidonate secretion - for enabling the reciprocal synthesis and secretion of PG by the conceptus - is a key step in ruminant maternal-embryo communication.

Ribeiro et al. (2016a) found three arachidonatederivatives - prostaglandins, 15-hydroxyeicosatetraenoic acid (15-HETE) and anandamide - elevated in pregnant vs cyclic animals on Day 15. These were not identified here; however, the closely related 12-hydroxyeicosatetraenoic acid (12-HETE) was (Table 1). Interestingly, 12-HETE, like 15-HETE, is a natural ligand of the peroxisome proliferator-activated receptor gamma (PPAR $\gamma$ ) (Li et al. 2004) - a transcription factor shown to upregulate genes 
whose proteins stimulate lipid uptake and adipogenesis in a ligand-dependent manner (Jones et al. 2005). A 17-fold increase in PPAR $\gamma$ gene expression in the bovine trophectoderm on Day 15 (Ribeiro et al. 2016a) suggests it plays a role in the upstream regulation of the conceptus transcriptome (Ribeiro 2018), in addition to implantation - murine uterine implantation sites were reduced in a uterine environment depleted of 12- and 15-HETE, likely owing to reduced PPAR $\gamma$ activity (Li et al. 2004). In spite of the aforementioned, several unknowns surrounding the mechanism by which PPAR $\gamma$ supports conceptus development remain, notwithstanding the question of the extent to which PPAR $\gamma$ gene expression is endogenously activated by the conceptus as opposed to by ULF, owing to the fact that PPARy ligands, such as polyunsaturated fatty acids and 12-HETE, displayed modest flux in this study (Fig. 5).

Regarding signalling, myo-inositol, which showed a day by P4 effect (Fig. 1 and Table 1 ) is the precursor of numerous secondary messengers involved in regulating a diverse array of core cellular processes including fat catabolism (Rapiejko et al. 1986), cytoskeletal assembly and remodelling (Berridge 1987), calcium signalling (Berridge \& Irvine 1989, Downes \& Macphee 1990), cell membrane potential homeostasis (Kukuljan et al. 1997) and gene expression (Shen et al. 2003, Steger et al. 2003). Within a reproductive context, myo-inositol incorporation to in vitro embryo culture medium with citrate improved bovine blastocyst development rates (Holm et al. 1999), and human oocyte quality following in vivo and in vitro supplementation (Vitale et al. 2016). Myo-inositol may additionally interact with uterine epithelial and luminal glycerolipid and phospholipid metabolism, which also exhibited day by P4 interaction enrichment (Fig. 3). Specifically, cytidine diphosphoglyceride-inositol transferase an enzyme highly abundant in most mammalian cell types (Antonsson 1997) including the bovine mammary tissue (Wootton \& Kinsella 1977) - utilizes myo-inositol to remove CDP-diacylglycerol from the glycerophospholipid pathways via the formation of phosphatidyl-1D-myo-inositol (Bleasdale et al. 1979). Interestingly, the closely related enzyme 1-phosphatidyl1D-myo-inositol-3-phosphate 5-kinase has been identified in the ULF of pregnant heifers on Day 16 (Forde et al. 2014). Thus, further research is warranted to pin-point the potential signalling role of myo-inositol in maternal-embryo communication, although the trend towards increased myo-inositol abundance on Day 14 in high P4 heifers (Fig. 5) indicates that myo-inositol may play a more prominent role in sustaining, rather than initiating, conceptus elongation.

\section{Additional considerations}

In this study, untargeted (de novo) UPLC-MS/MS screening, as opposed to targeted (a priori) analyte identification, was utilized to explore the lipidomic landscape of ULF. Whilst this allows for the identification of a very wide panel of metabolites, it is not without technical limitations, namely compromised quantitative accuracy due to a lack of authentic standards. This is largely attributable to ion suppression on account of a highly abundant metabolite co-eluting with a subsequent metabolite or ionisation efficiency inconsistencies due to sample matrix variations (Baig et al. 2016). Efforts to minimise such biases include (a) incorporating recovery standards prior to the first step of the extraction process for quality control purposes, (b) injecting an aliquot from a pool of each experimental sample at random intervals throughout each platform day-run as a technical replicate, from which a $5 \%$ technical median relative standard deviation was determined and (c) providing semi-quantitative data comparisons.

Fromanexperimental perspective, storagetemperature, freeze thaw cycles and even sample container materials can affect observed biochemical profiles (Scalbert et al. 2009). Whilst all samples were handled identically in this study, enabling accurate metabolite comparisons between groups, caution is advised when comparing data quantitatively across studies. Moreover, biochemical promiscuity (i.e. molecules involved in $>1$ pathway) instils a degree of speculation into subsequent pathway analyses. However, overcoming this by using radiolabelled isotopes (e.g. carbon tracking) in in vivo large animal studies is both ethically and technically challenging (Aretz \& Meierhofer 2016).

Lastly, it is important to highlight that - whilst high P4 was the independent experimental variable of this study - the discussion revolves around lipid metabolites exhibiting a day by P4 interaction, as opposed to a P4 main effect, as conceptus elongation is influenced by both time and P4. Nonetheless, in the interest of completeness, P4 main effect data have been provided, in addition to day main effect comparisons; the latter also providing valuable information pertinent to the changes in ULF which drive elongation under physiological conditions.

\section{Summary}

This study expands on previous work interrogating the molecular biology surrounding maternal-embryo communication by utilizing existing high-throughput metabolomics technologies for the novel application of exploring the environment evolved to facilitate the fundamental developmental process of conceptus elongation in high resolution. The data show that (a) a high P4 environment consistent with advanced conceptus elongation increases total lipid abundance on Day 14, (b) $47 \%$ of identified lipids intricately link to membrane biochemistry and (c) $50 \%$ of the metabolic pathways displaying a day by P4 interaction enrichment in ULF during Days 12-14 revolve around glycerophospholipid 
metabolism. The combined data suggest that maternal lipid supply during the elongation window is primarily geared towards conceptus membrane biogenesis.

\section{Supplementary data}

This is linked to the online version of the paper at https://doi.org/10.1530/REP-18-0615.

\section{Declaration of interest}

The authors declare that there is no conflict of interest that could be perceived as prejudicing the impartiality of the research reported.

\section{Funding}

This work was supported by Science Foundation Ireland (13/IA/1983), an Irish Research Council Government of Ireland Postdoctoral Fellowship (GIOPD/2017/942), and a University College Dublin (UCD) Career Development Award (CDA54580).

\section{Author contribution statement}

C A S and P L conceived the idea. C A S, J M S and P L designed the research. C A S, J M S and M M performed the research. C A S and P L analysed the data and wrote the manuscript.

\section{Acknowledgements}

The authors additionally thank the staff at Kildare Chilling Company, John Furlong and Dr Alan Kelly at UCD, Dr Patricia A. Sheridan, Dr Ed Karoly, and Dr Robert Mohney at Metabolon Inc. in addition to the students and staff at UCD Lyons Research Farm.

\section{References}

Antonsson B 1997 Phosphatidylinositol synthase from mammalian tissues. Biochimica et Biophysica Acta 1348 179-186. (https://doi.org/10.1016/ S0005-2760(97)00105-7)

Aretz I \& Meierhofer D 2016 Advantages and pitfalls of mass spectrometry based metabolome profiling in systems biology. International Journal of Molecular Sciences 17 1-14. (https://doi.org/10.3390/ijms17050632)

Baig F, Pechlaner R \& Mayr M 2016 Caveats of untargeted metabolomics for biomarker discovery. Journal of the American College of Cardiology 68 1294-1296. (https://doi.org/10.1016/j.jacc.2016.05.098)

Barnwell CV, Farin PW, Ashwell CM, Farmer WT, Galphin SP \& Farin CE 2016 Differences in mRNA populations of short and long bovine conceptuses on Day 15 of gestation. Molecular Reproduction and Development 83 424-441. (https://doi.org/10.1002/mrd.22640)

Bazer FW 2013 Pregnancy recognition signaling mechanisms in ruminants and pigs. Journal of Animal Science and Biotechnology 4 23. (https://doi. org/10.1186/2049-1891-4-23)

Bazer FW, Wu G \& Johnson GA 2017 Pregnancy recognition signals in mammals: the roles of interferons and estrogens. Animal Reproduction 14 7-29. (https://doi.org/10.21451/1984-3143-AR888)

Berg DK, Smith CS, Pearton DJ, Wells DN, Broadhurst R, Donnison M \& Pfeffer PL 2011 Trophectoderm lineage determination in cattle.
Developmental Cell $20 \quad$ 244-255. (https://doi.org/10.1016/j. devcel.2011.01.003)

Berridge MJ 1987 Inositol trisphosphate and diacylglycerol: two interacting second messengers. Annual Review of Biochemistry 56 159-193. (https://doi.org/10.1146/annurev.bi.56.070187.001111)

Berridge MJ \& Irvine RF 1989 Inositol phosphates and cell signalling. Nature 341 197-205. (https://doi.org/10.1038/341197a0)

Betteridge KJ, Eaglesome MD, Randall GC \& Mitchell D 1980 Collection, description and transfer of embryos from cattle 10-16 days after oestrus. Journal of Reproduction and Fertility 59 205-216. (https://doi. org/10.1530/jrf.0.0590205)

Binelli M, Thatcher WW, Mattos R \& Baruselli PS 2001 Antiluteolytic strategies to improve fertility in cattle. Theriogenology 56 1451-1463. (https://doi.org/10.1016/S0093-691X(01)00646-X)

Bleasdale JE, Wallis P, MacDonald PC \& Johnston JM 1979 Characterization of the forward and reverse reactions catalyzed by CDP-diacylglycerol: inositol transferase in rabbit lung tissue. Biochimica et Biophysica Acta 575 135-147. (https://doi.org/10.1016/0005-2760(79)90139-5)

Boshier DP, Fairclough RJ \& Holloway H 1987 Assessment of sheep blastocyst effects on neutral lipids in the uterine caruncular epithelium. Journal of Reproduction and Fertility 79 569-573. (https://doi. org/10.1530/jrf.0.0790569)

Brandão DO, Maddox-Hyttel P, Løvendahl P, Rumpf R, Stringfellow D \& Callesen H 2004 Post hatching development: a novel system for extended in vitro culture of bovine embryos. Biology of Reproduction 71 2048-2055. (https://doi.org/10.1095/biolreprod.103.025916)

Brinsfield TH \& Hawk HW 1973 Control by progesterone of the concentration of lipid droplets in epithelial cells of the sheep endometrium. Journal of Animal Science 36 919-922. (https://doi.org/10.2527/jas1973.365919x)

Brooks K, Burns G \& Spencer TE 2014 Conceptus elongation in ruminants: roles of progesterone, prostaglandin, Interferon tau and cortisol. Journal of Animal Science and Biotechnology 5 53. (https://doi.org/10.1186/20491891-5-53)

Brown DG, Rao S, Weir TL, O'Malia J, Bazan M, Brown RJ \& Ryan EP 2016 Metabolomics and metabolic pathway networks from human colorectal cancers, adjacent mucosa, and stool. Cancer and Metabolism 411. (https://doi.org/10.1186/s40170-016-0151-y)

Burns G, Brooks K, Wildung M, Navakanitworakul R, Christenson LK \& Spencer TE 2014 Extracellular vesicles in luminal fluid of the ovine uterus. PLOS ONE 9 e90913. (https://doi.org/10.1371/journal. pone.0090913)

Burns GW, Brooks KE, O'Neil EV, Hagen DE, Behura SK \& Spencer TE 2018 Progesterone effects on extracellular vesicles in the sheep uterus. Biology of Reproduction 98 612-622. (https://doi.org/10.1093/biolre/ioy011)

Cao H, Xiao L, Park GY, Wang X, Azim AC, Christmas JW \& van Breemen RB 2008 An improved LC-MS-MS method for the quantification of prostaglandins E2 and D2 production in biological fluids. Analytical Biochemistry 372 41-51. (https://doi.org/10.1016/j.ab.2007.08.041)

Carter F, Forde N, Duffy P, Wade M, Fair T, Crowe MA, Evans ACO, Kenny DA, Roche JF \& Lonergan P 2008 Effect of increasing progesterone concentration from Day 3 of pregnancy on subsequent embryo survival and development in beef heifers. Reproduction, Fertility, and Development 20 368-375. (https://doi.org/10.1071/RD07204)

Clemente M, De La Fuente J, Fair T, Al Naib A, Gutierrez-Adan A, Roche JF, Rizos D \& Lonergan P 2009 Progesterone and conceptus elongation in cattle: a direct effect on the embryo or an indirect effect via the endometrium? Reproduction 138 507-517. (https://doi.org/10.1530/ REP-09-0152)

Degrelle SA, Campion E, Cabau C, Piumi F, Reinaud P, Richard C, Renard JP \& Hue I 2005 Molecular evidence for a critical period in mural trophoblast development in bovine blastocysts. Developmental Biology 288 448-460. (https://doi.org/10.1016/j.ydbio.2005.09.043)

Diskin MG \& Sreenan JM 1980 Fertilization and embryonic mortality rates in beef heifers after artificial insemination. Journal of Reproduction and Fertility 59 463-468. (https://doi.org/10.1530/jrf.0.0590463)

Do KT, Wahl S, Raffler J, Molnos S, Laimighofer M, Adamski J, Suhre K, Strauch K, Peters A, Gieger C et al. 2018 Characterization of missing values in untargeted MS-based metabolomics data and evaluation of missing data handling strategies. Metabolomics 14 128. (https://doi. org/10.1007/s11306-018-1420-2)

Dorniak P, Bazer FW \& Spencer TE 2011 Prostaglandins regulate conceptus elongation and mediate effects of interferon tau on the ovine 
uterine endometrium. Biology of Reproduction 84 1119-1127. (https:// doi.org/10.1095/biolreprod.110.089979)

Downes CP \& Macphee CH 1990 Myo-inositol metabolites as cellular signals. European Journal of Biochemistry 193 1-18. (https://doi. org/10.1111/j.1432-1033.1990.tb19297.x)

Forde N \& Lonergan P 2017 Interferon-tau and fertility in ruminants. Reproduction 154 F33-F43. (https://doi.org/10.1530/REP-17-0432)

Forde N, Carter F, Fair T, Crowe MA, Evans ACO, Spencer TE, Bazer FW, McBride R, Boland MP, O'Gaora P et al. 2009 Progesterone-regulated changes in endometrial gene expression contribute to advanced conceptus development in cattle. Biology of Reproduction 81 784-794. (https://doi.org/10.1095/biolreprod.108.074336)

Forde N, Mehta JP, Minten M, Crowe MA, Roche JF, Spencer TE \& Lonergan P 2012 Effects of low progesterone on the endometrial transcriptome in cattle. Biology of Reproduction 87 124. (https://doi. org/10.1095/biolreprod.112.103424)

Forde N, McGettigan PA, Mehta JP, O'Hara L, Mamo S, Bazer FW, Spencer TE \& Lonergan P 2014 Proteomic analysis of uterine fluid during the pre-implantation period of pregnancy in cattle. Reproduction 147 575-587. (https://doi.org/10.1530/REP-13-0010)

Gibbons R, Adeoya-Osiguwa SA \& Fraser LR 2005 A mouse sperm decapacitation factor receptor is phosphatidylethanolamine-binding protein 1. Reproduction 130 497-508. (https://doi.org/10.1530/ rep.1.00792)

Giller K, Drews B, Berard J, Kienberger H, Schmicke M, Frank J, Spanier B \& Daniel H 2018 Bovine embryo elongation is altered due to maternal fatty acid supplementation. Biology of Reproduction 99 600-610. (https://doi.org/10.1093/biolre/ioy084)

Gray CA, Taylor KM, Ramsey WS, Hill JR, Bazer FW, Bartol FF. \& Spencer TE 2001 Endometrial glands are required for preimplantation conceptus elongation and survival. Biology of Reproduction 64 1608-1613. (https://doi.org/10.1095/biolreprod64.6.1608)

Guillomot M 1995 Cellular interactions during implantation in domestic ruminants. Journal of Reproduction and Fertility. Supplement 49 39-51.

Hengst U, Albrecht H, Hess D \& Monard D 2001 The phosphatidylethanolamine-binding protein is the prototype of a novel family of serine protease inhibitors. Journal of Biological Chemistry $\mathbf{2 7 6}$ 535-540. (https://doi.org/10.1074/jbc.M002524200)

Holm P, Booth PJ, Schmidt MH, Greve T \& Callesen H 1999 High bovine blastocyst development in a static in vitro production system using SOFaa medium supplemented with sodium citrate and myo-inositol with or without serum proteins. Theriogenology 52 683-700. (https:// doi.org/10.1016/S0093-691X(99)00162-4)

Hue I, Degrelle SA \& Turenne N 2012 Conceptus elongation in cattle: genes, models and questions. Animal Reproduction Science 134 19-28. (https://doi.org/10.1016/j.anireprosci.2012.08.007)

Jones JR, Barrick C, Kim KA, Lindner J, Blondeau B, Fujimoto Y, Shiota M, Kesterson RA, Kahn BB \& Magnuson MA 2005 Deletion of PPAR in adipose tissues of mice protects against high fat diet-induced obesity and insulin resistance. PNAS 102 6207-6212. (https://doi.org/10.1073/ pnas.0306743102)

Kerbler TL, Buhr MM, Jordan LT, Leslie KE \& Walton JS 1997 Relationship between maternal plasma progesterone concentration and interferontau synthesis by the conceptus in cattle. Theriogenology 47 703-714. (https://doi.org/10.1016/S0093-691X(97)00028-9)

Kukuljan M, Vergara L \& Stojikovic SS 1997 Modulation of the kinetics of inositol 1,4,5-Trisphosphate-Induced [Ca2+]l oscillations by calcium entry in pituitary gonadotrophs. Biophysical Journal 72 698-707. (https:// doi.org/10.1016/S0006-3495(97)78706-X)

Lewis GS \& Waterman RA 1983 Effects of endometrium on metabolism of arachidonic acid by bovine blastocysts in vitro. Prostaglandins $\mathbf{2 5}$ 881-889. (https://doi.org/10.1016/0090-6980(83)90011-4)

Li Q, Cheon YP, Kannan A, Shanker S, Bagchi IC \& Bagchi MK 2004 A novel pathway involving progesterone receptor, 12/ 15-lipoxygenasederived eicosanoids, and peroxisome proliferator-activated receptor $\gamma$ regulates implantation in mice. Journal of Biological Chemistry 279 11570-11581. (https://doi.org/10.1074/jbc.M311773200)

Lonergan P 2015 New insights into the function of progesterone in early pregnancy. Animal Frontiers 5 12-17. (https://doi.org/10.2527/af.20150003)

Mamo S, Mehta JP, McGettigan P, Fair T, Spencer TE, Bazer FW \& Lonergan P 2011 RNA sequencing reveals novel gene clusters in bovine conceptuses associated with maternal recognition of pregnancy and implantation. Biology of Reproduction 85 1143-1151. (https://doi. org/10.1095/biolreprod.111.092643)

Muro E, Atilla-Gokcumen GE \& Eggert US 2014 Lipids in cell biology: how can we understand them better? Molecular Biology of the Cell 25 1819-1823. (https://doi.org/10.1091/mbc.E13-09-0516)

O'Hara L, Forde N, Kelly AK \& Lonergan P 2014 a Effect of bovine blastocyst size at embryo transfer on day 7 on conceptus length on day 14: can supplementary progesterone rescue small embryos? Theriogenology $\mathbf{8 1}$ 1123-1128. (https://doi.org/10.1016/j.theriogenology.2014.01.041)

O'Hara L, Forde N, Carter F, Rizos D, Maillo V, Ealy AD, Kelly AK, Rodriguez P, Isaka N, Evans ACO et al. 2014b Paradoxical effect of supplementary progesterone between day 3 and day 7 on corpus luteum function and conceptus development in cattle. Reproduction, Fertility, and Development 26 328-336. (https://doi.org/10.1071/RD12370)

Rapiejko PJ, Northup JK, Evans T, Brown JE \& Malbon CC 1986 G-proteins of fat-cells. Role in hormonal regulation of intracellular inositol 1,4,5-trisphosphate. Biochemical Journal 240 35-40. (https://doi. org/10.1042/bj2400035)

Resh MD 2016 Fatty acylation of proteins: the long and the short of it. Progress in Lipid Research 63 120-131. (https://doi.org/10.1016/j. plipres.2016.05.002)

Ribeiro ES 2018 Symposium review: Lipids as regulators of conceptus development: implications for metabolic regulation of reproduction in dairy cattle. Journal of Dairy Science 101 3630-3641. (https://doi. org/10.3168/jds.2017-13469)

Ribeiro ES, Greco LF, Bisinotto RS, Lima FS, Thatcher WW \& Santos JE 2016 a Biology of preimplantation conceptus at the onset of elongation in dairy cows. Biology of Reproduction 94 97. (https://doi.org/10.1095/ biolreprod.115.134908)

Ribeiro ES, Gomes G, Greco LF, Cerri RLA, Vieira-Neto A, Monteiro PLJ, Lima FS, Bisinotto RS, Thatcher WW \& Santos JEP 2016b Carryover effect of postpartum inflammatory diseases on developmental biology and fertility in lactating dairy cows. Journal of Dairy Science 99 2201-2220. (https://doi.org/10.3168/jds.2015-10337)

Ribeiro ES, Santos JEP \& Thatcher WW 2016c Role of lipids on elongation of the preimplantation conceptus in ruminants. Reproduction 152 R115-R126. (https://doi.org/10.1530/REP-16-0104)

Rizos D, Scully S, Kelly AK, Ealy AD, Moros R, Duffy P, Al Naib A, Forde N \& Lonergan P 2012 Effects of human chorionic gonadotrophin administration on Day 5 after oestrus on corpus luteum characteristics, circulating progesterone and conceptus elongation in cattle. Reproduction, Fertility, and Development 24 472-481. (https://doi. org/10.1071/RD11139)

Saliba AE, Vonkova I \& Gavin AC 2015 The systematic analysis of proteinlipid interactions comes of age. Nature Reviews Molecular Cell Biology 16 753-761. (https://doi.org/10.1038/nrm4080)

Scalbert A, Brennan L, Fiehn O, Hankemeier T, Kristal BS, Ommen B Van, Pujos-Guillot E, Verheij E, Wishart D \& Wopereis S 2009 Massspectrometry-based metabolomics: limitations and recommendations for future progress with particular focus on nutrition research. Metabolomics 5 435-458. (https://doi.org/10.1007/s11306-009-0168-0)

Shen X, Xiao H, Ranallo R, Wu WH \& Wu C 2003 Modulation of ATPdependent chromatin-remodeling complexes by inositol polyphosphates. Science 299 112-114. (https://doi.org/10.1126/science.1078068)

Simintiras CA, Sanchez JM, McDonald M, Martins T, Binelli M \& Lonergan P 2018 Biochemical characterization of progesterone-induced alterations in bovine uterine fluid amino acid and carbohydrate composition during the conceptus elongation window. Biology of Reproduction Epub. (https://doi.org/10.1093/biolre/ioy234)

Spencer TE, Forde N \& Lonergan P 2016 Insights into conceptus elongation and establishment of pregnancy in ruminants. Reproduction, Fertility, and Development 29 84-100. (https://doi.org/10.1071/RD16359)

Steger DJ, Haswell ES, Miller AL, Wente SR \& O'Shea EK 2003 Regulation of chromatin remodeling by inositol polyphosphates. Science 299 114-116. (https://doi.org/10.1126/science.1078062)

Thukral L, Sengupta D, Ramkumar A, Murthy D, Agrawal N \& Gokhale RS 2015 The molecular mechanism underlying recruitment and insertion of lipid-anchored LC3 protein into membranes. Biophysical Journal 109 2067-2078. (https://doi.org/10.1016/j.bpj.2015.09.022)

Ulbrich SE, Schulke K, Groebner AE, Reichenbach HD, Angioni C, Geisslinger G \& Meyer HHD 2009 Quantitative characterization of 
prostaglandins in the uterus of early pregnant cattle. Reproduction 138 371-382. (https://doi.org/10.1530/REP-09-0081)

Vallée BS, Tauc P, Brochon JC, Maget-Dana R, Lelièvre D, MetzBoutigue MH, Bureaud N \& Schoentgen F 2001 Behaviour of bovine phosphatidylethanolamine-binding protein with model membranes: evidence of affinity for negatively charged membranes. European Journal of Biochemistry 268 5831-5841. (https://doi.org/10.1046/j.00142956.2001.02528.x)

van Meer G \& de Kroon AIPM 2011 Lipid map of the mammalian cell. Journal of Cell Science 124 5-8. (https://doi.org/10.1242/jcs.071233)

van Meer G, Voelker DR \& Feigenson GW 2008 Membrane lipids: where they are and how they behave. Nature Reviews Molecular Cell Biology 9 112-124. (https://doi.org/10.1038/nrm2330)

Vilella F, Ramirez LB \& Simón C 2013 Lipidomics as an emerging tool to predict endometrial receptivity. Fertility and Sterility 99 1100-1106. (https://doi.org/10.1016/j.fertnstert.2012.12.026)

Vitale SG, Rossetti P, Corrado F, Rapisarda AMC, La Vignera S, Condorelli RA, Valenti G, Sapia F, Laganà AS \& Buscema M 2016 How to achieve high-quality oocytes? The key role of myo-inositol and melatonin. International Journal of Endocrinology 2016 1-9. (https://doi. org/10.1155/2016/4987436)

Wales RG \& Cuneo CL 1989 Morphology and chemical analysis of the sheep conceptus from the 13th to the 19th day of pregnancy. Reproduction, Fertility, and Development 1 31-39. (https://doi. org/10.1071/RD9890031)
Walsh SW, Williams EJ \& Evans ACO 2011 A review of the causes of poor fertility in high milk producing dairy cows. Animal Reproduction Science 123 127-138. (https://doi.org/10.1016/j.anireprosci.2010.12.001)

Weems CW, Weems YS \& Randel RD 2006 Prostaglandins and reproduction in female farm animals. Veterinary Journal 171 206-228. (https://doi. org/10.1016/j.tvjl.2004.11.014)

Wiltbank MC, Baez GM, Garcia-Guerra A, Toledo MZ, Monteiro PLJ, Melo LF, Ochoa JC, Santos JEP \& Sartori R 2016 Pivotal periods for pregnancy loss during the first trimester of gestation in lactating dairy cows. Theriogenology 86 239-253. (https://doi.org/10.1016/j. theriogenology.2016.04.037)

Wootton JA \& Kinsella JE 1977 Properties of cytidinediphosphodiacyl-snglycerol: myoinositol transferase of bovine mammary tissue. International Journal of Biochemistry 8 449-456. (https://doi.org/10.1016/0020711X(77)90045-3)

Received 6 December 2018

First decision 17 January 2019

Revised manuscript received 28 January 2019

Accepted 14 February 2019 